Resumo Número: 18198

\title{
Tratamento da lesão da sindesmose tibiofibular distal nas fraturas do tornozelo com 0 suture button
}

\author{
Guilherme Honda Saito ${ }^{1}$, Marcelo Pires Prado ${ }^{1}$, Alberto Abussamra Moreira Mendes ${ }^{1}$, Danilo Ryuko Nishikawa², \\ Beatriz Devito ${ }^{1}$, Leticia Devito ${ }^{1}$ \\ 1. Hospital Israelita Albert Einstein, São Paulo, SP, Brasil. \\ 2. Hospital do Servidor Público Municipal de São Paulo, São Paulo, SP, Brasil.
}

\section{RESUMO}

Introdução: O tratamento convencional das lesões da sindesmose tibiofibular distal (STFD) nas fraturas do tornozelo é feita com a fixação da STFD, com parafusos estabilizadores. Porém, parafusos podem acarretar em problemas devido à sua rigidez inerente. Por esse motivo, houve aumento da popularidade de dispositivos de fixação que permitam mobilidade da STFD. O objetivo do presente estudo é descrever os resultados obtidos no tratamento cirúrgico das fraturas do tornozelo com lesão da STFD através da fixação da sindesmose com o suture button.

Métodos: Quarenta e quatro pacientes tratados cirurgicamente com o uso do suture button devido a fraturas do tornozelo associadas à lesão da STFD foram retrospectivamente analisados. O tempo de seguimento médio dos pacientes foi de 14,7 meses. Os pacientes foram avaliados em relação ao nível funcional pelo score AOFAS, escala de dor (VAS), taxa de complicações e necessidade de reoperações.

Resultados: O score AOFAS médio no último follow-up foi de 92 (35-100). O VAS médio foi de 0,8 (0-7). Oito pacientes (18\%) evoluíram com complicações, sendo as mais comuns osteoartrose pós-traumática e tendinopatia dos fibulares. Reoperações foram realizadas em 6 pacientes $(13,5 \%)$, e incluíram retirada de material de síntese, tenoplastia dos fibulares, neurólise ou artrodese tibiofibular distal. Apenas um paciente não conseguiu retornar às atividades prévias.

Conclusão: O suture button demonstrou ser uma alternativa confiável para fixação da STFD nas fraturas do tornozelo, propiciando excelentes resultados funcionais com baixo índice de complicações. Esse dispositivo possui a vantagem teórica de permitir a mobilidade fisiológica da articulação tibiofibular distal e em geral não requerer a retirada do material de síntese em um segundo tempo.

Palavras-chave: Articulação tibiofibular distal; Traumatismos do tornozelo; Ligamentos. 